\title{
Internet and Fuzzy Based Control System for Rotary Kiln in Cement Manufacturing Plant
}

\author{
Hanane Zermane, ${ }^{1}$ Hayet Mouss ${ }^{2}$ \\ 12 Industrial Engineering Department, University Batna 2, \\ Batna, 05000, Algeria \\ E-mail: hananezermane@yahoo.fr \\ E-mail:hayet_mouss@yahoo.fr \\ Received 9 February 2016
}

Accepted 17 March 2017

\begin{abstract}
This paper develops an Internet-based fuzzy control system for an industrial process plant to ensure the remote and fuzzy control in cement factories in Algeria. The remote process consists of control, diagnosing alarms occurs, maintaining and synchronizing different regulation loops. Fuzzy control of the kiln ensures that the system be operational at all times, with minimal downtime. Internet technology ensures remote control. The system reduces downtimes and can guided by operators in the main control room or via Internet.
\end{abstract}

Keywords: Fuzzy control, remote control, industrial networks, data acquisition, e-diagnostic.

\section{Introduction}

"As the complexity of a system increases, our ability to make precise and yet significant statements about its behavior diminishes until a threshold is reached beyond which precision and significance (or relevance) become almost mutually exclusive characteristics" 1 .

In reasoning about a complex system, humans reason approximately about its behavior, thereby maintaining only a generic understanding about the problem.

Fortunately, this generality and ambiguity are sufficient for human comprehension of complex systems. As the quote above from Zadeh's principle of incompatibility suggests, complexity and ambiguity (imprecision) are correlated: "The closer one looks at a real-world problem, the fuzzier becomes its solution" ${ }^{1}$.
Lotfi Zadeh initiated a Fuzzy Logic technique to resolve uncertain reasoning problems. Therefore, Fuzzy logic is a method to formalize the human capacity of imprecise reasoning, or approximate reasoning. Such reasoning represents the human ability to reason approximately and judge under uncertainty. In fuzzy logic all truths are partial or approximate.

In this sense, this reasoning has also been termed interpolative reasoning, where the process of interpolating between the binary extremes of true and false represented by the ability of fuzzy logic to encapsulate partial truths.

Fuzzy Logic applied in industry for process control. Where control applications are the kinds of problems for which fuzzy logic has had the greatest success and acclaim. Many of the consumer products that we use today involve fuzzy control.

Developers in cement factories need to integrate ar- 
tificial intelligence techniques such as fuzzy logic ${ }^{2}$. However, technology is not limited on application of Fuzzy Logic. Actually, many industrial control systems have features for access over the Internet. As opposed to real-time feedback control, these features are intended for enterprise-wide visibility and monitoring purposes.

Supervisory control and monitoring over the Internet often used rather than real-time feedback control. It is now possible to access process setups and instruments remotely and gain access to real-time data anytime anywhere. The system can be set up for access over the Internet using a web browser.

Cement industry is one of the process systems trying to be developed. In this case, growing competition forces cement factories to reduce costs, continually increase productivity and quality, reduce the time required for marketing products, and develop technologies and clean production processes based on optimal use of raw materials and energy.

To achieve these aims, it is necessary to continuously optimize processes, modernize, and develop the systems and facilities.

In order to avoid human errors and inaccuracies during manual data collection from different parts of the installation, it is wise to avoid wasting human resources through the automation of certain procedures, ensure performance and uniform documentation for all production facilities, provide evaluation reports required and keep records of important data for historical analysis.

\section{Proposed Approach}

To evolve the system, we propose a novel approach. Firstly, we applied an artificial intelligence technique, which is fuzzy logic, where we integrated the fuzzy control of different workshops of kiln and the two mills, which ensures that the system is operational at all times, with minimal downtime.

Secondly, we integrated Internet technology, where the remote control via Internet, used for security of human life and rendering it unnecessary for operators to be at the site for maintenance.

In addition, when there is a breakdown it is not necessary to send an expert to diagnose and solve the problem because it is difficult to organize visas, flight, etc. Therefore, the proposed system reduces downtimes and travel costs by the possibility of sending reports and transmitting all process data. The process control system contains different operators' stations, alarms and trends tables. The operator can execute any operation according to his authentication access. We applied Internet technologies to develop a fuzzy control system based on Internet access for an industrial process plant.

The system created to optimize the process control in different cement factories in Algeria. Until 2016, none cement industry apply neither fuzzy control nor Internet-based control in his production system. The implementation of the new industrial network architecture programming based on Siemens tools, such as, PCS 7, and FuzzyControl++.

\section{Cement Production Process}

Cement sector plays an important role within the building materials industry. Productivity and product quality are the decisive factors on the international stage. The cement industry, with its high level of energy and raw materials use, is particularly concerned with conserving natural resources and protecting the global climate.

Cement sector must keep pace with scientific and technological developments. Such is necessary to meet consumer expectations, remain competitive, while also lowering costs. This can achieved by applying a strict management policy that enables the control of production.

An economic cement production strongly depends on energy efficiency in production processes and on securing a high product quality. Hereby, the coincineration of alternative fuels in substituting primary fuels is gaining more importance.

Therefore, it is necessary to monitor continuously the processes with analyzing systems, also in order to comply with the relevant emission limit values. Cement production process includes many workshops.

Fig. 1. presents the cement production process from the extraction of raw materials to the distribution of the final product. 


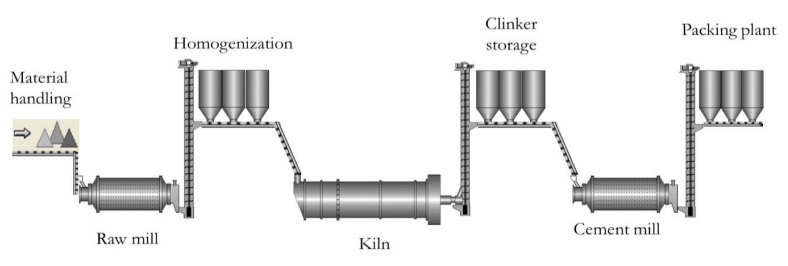

Fig. 1. Cement process.

Clinker and cement production is an intensive process in terms of natural raw material and energy input. Where limestone (primary source of calcium carbonate $\mathrm{CaCO}_{3}$ ) and clay (primary source of silica $\mathrm{SiO}_{2}$, alumina $\mathrm{Al}_{2} \mathrm{O}_{3}$ and iron oxide $\mathrm{Fe}_{2} \mathrm{O}_{3}$ ) are mined in company-owned quarries and pre-blended to a target chemical material composition.

Corrective materials like sand, iron ore, bauxite or industrial waste materials (alternative raw materials) are then used to fine-tune and correct the chemical composition of this pre-blend material in the raw mill. Fine ground raw meal is then stored and further homogenized in the raw meal silo. Raw grinding process is presented in Fig. 2.

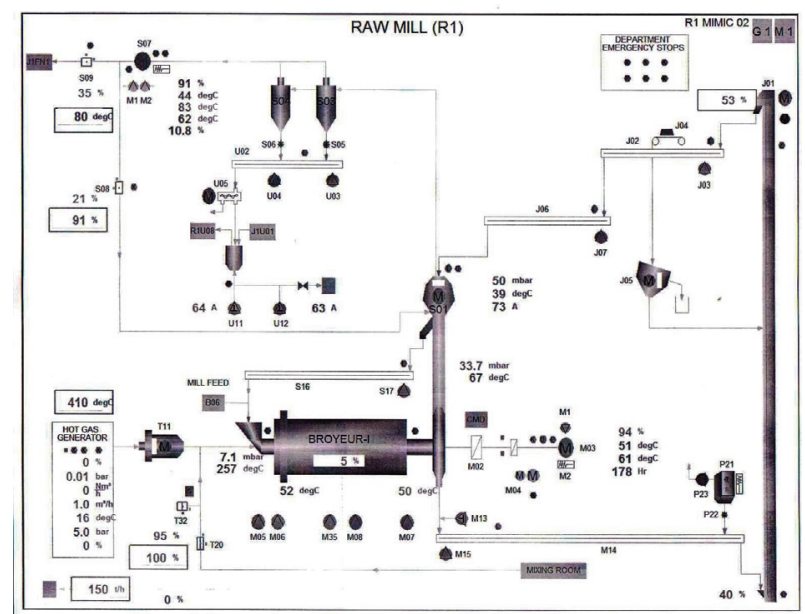

Fig. 2. Raw grinding process.

A kiln system consists of a static preheating system with typically five cyclone stages and a precalcining. The raw meal (so-called kiln feed) is heated up to $1000^{\circ} \mathrm{C}$ and the calcium carbonate portion is calcined: $\mathrm{CaCO}_{3}=\mathrm{CaO}+\mathrm{CO}_{2}$. In the attached rotary kiln, the material is then heated up to $1450^{\circ} \mathrm{C}$ and Portland cement clinker is formed.

Clinker is an assembly of four artificial miner- als (Alite $\left(\mathrm{Ca}_{3} \mathrm{SiO}_{5}\right)$, Belite $\left(\mathrm{Ca}_{2} \mathrm{SiO}_{4}\right)$, Tricalcium aluminate $\left(\mathrm{Ca}_{3} \mathrm{Al}_{2} \mathrm{O}_{6}\right)$ and ferrite) which have hydraulic properties, i.e. they harden when mixed with water. Fast cooling and freezing of these artificial minerals then happens in the clinker cooler, the third element of a cement kiln system. A crucial ingredient to make this mineral transformation happen is the fuel. Historically oil and gas were used, then coal and petcock, but since the 1980s more and more alternative fuels are employed for heating. Here it must be highlighted that the fuel ash is incorporated fully in the clinker so the final clinker composition is always the sum of the calcined raw meal and the remaining fuel ash after burnout of the fuel.

Clinker is the important intermediate product stage in cement manufacturing and traded worldwide as a commodity between cement producers. Cement produced by mixing, fine-grinding clinker, gypsum and mineral components in cement mills. Gypsum is added to control cement setting, i.e. the hardening process.

Mineral components are added to reduce the clinker portion in cements and introduce special product properties. Pure Ordinary Portland Cements (OPC) contain only clinker and gypsum; blended cements are the ones with mineral components ${ }^{3}$. Fig. 3. presents cement grinding process.

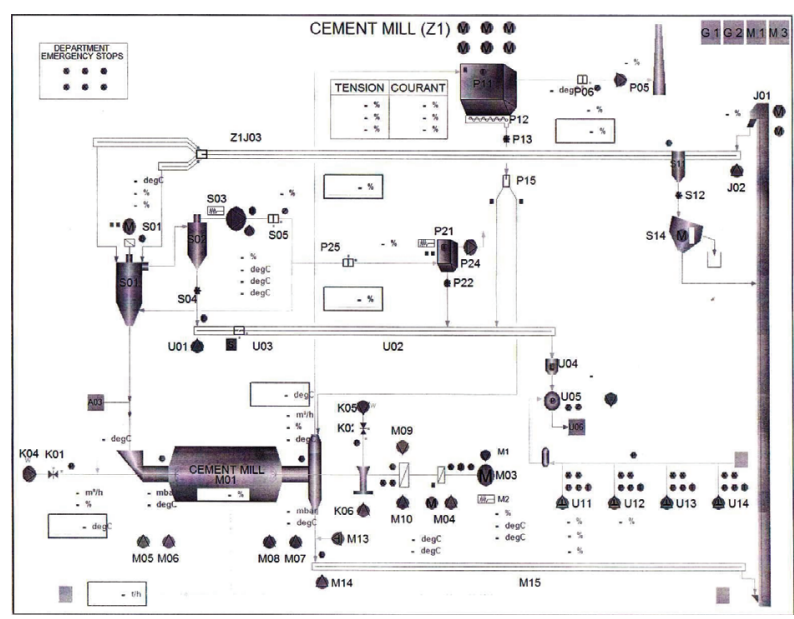

Fig. 3. Cement grinding process. 


\section{Fuzzy Logic in Cement Industry}

The increasing complexity in industrial systems explains the need for monitoring system performance. Security and reliability needs require the implementation of preferment solutions such as artificial intelligence techniques to control industrial processes. One such technique is fuzzy logic.

For its important value, fuzzy logic developed in several works ${ }^{4}$ and applied in different domains ${ }^{5}$. In complex systems such as cement manufacturing, one of the proposed fuzzy models is the TakagiSugeno (TS) fuzzy model, where fuzzy controllers used for process control can represent non-linear systems ${ }^{6}$.

FLSmidth Automation has been a pioneer in highlevel expert control systems for cement kiln applications. It is one of the initiative applied in cement factories such as SCIMAT in 1987. FLS has a new system based on fuzzy logic used in the cement industry, called ECS/ProcessExpert (ECS/PXP). It is a separate package, initiated after the stabilization of the system. The control system based on the famous industrial platform ECS (Expert Control \& Supervision) specially developed for remote monitoring, supervision and reporting.

ECS/PXP shown in Fig. 4. is a solution for control and optimization of complex high-level process, such as baking processes. The control is optimized using advanced functions PxP application, customized to meet the requirements of each user.

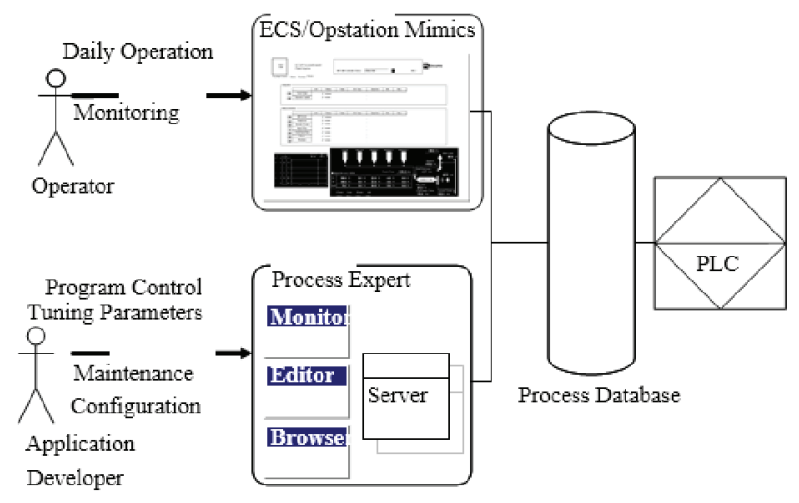

Fig. 4. ECS/ProcessExpert.

Depending on the type of application tech- niques, advanced expert system, fuzzy logic, neural networks, and a predictive model-based controller (MPC), are used in modules ProcessExpert application to allow patterns of hybrid control to meet the requirements of a given process control. These modules carry out regular assessments of complex and process conditions, and perform actions exercising better control and reliability than human operators 7. The control strategies behind ECS/PXP-Kiln is based on two decades of experience in cement kiln control and optimization ${ }^{8}$.

\section{Web-Based Process Control Works}

The globalization of the Internet has succeeded faster than anyone could have imagined. Innovators will use the Internet as a starting point for their efforts creating new products and services specifically designed to take advantage of the network capabilities. In the business world, the use of networks to provide efficient and cost-effective employee training is increasing in acceptance. On-line learning opportunities are cost and time efficient and ensure that all employees are adequately trained to perform their jobs in a safe and productive manner.

Data networks were initially used by businesses to internally record and manage financial information, customer information, and employee payroll systems. The intelligent communications platform offers much more than basic connectivity and access to applications including its use to control system experiments conducted remotely via the Internet ${ }^{9}$ for design issues and implementation of Internet-based process control systems ${ }^{10}$. In addition, other works use Wireless and Internet communications technologies for monitoring and control ${ }^{11}$, and for data acquisition and control of Display Systems (WSDS) for Access via Internet ${ }^{12}$. Some laboratory experiments attempted to apply web technologies to acquire information remotely ${ }^{13}$ or for remote supervision of industrial processes, using self-organizing maps ${ }^{14}$ to remote control and monitor web-based distributed OPC system ${ }^{15}$.

A web-based remote voice control of robotized cells was developed, based on the use of quasi-natural language. The main result of this research was 
the architecture of industrially oriented remote voice control system. ${ }^{16}$, to develop remote monitoring and control system for mechatronics engineering practice in the case of flexible manufacturing systems ${ }^{17}$. Another work represents a Web-Based Supervisory Control System Based on Raspberry $\mathrm{Pi}^{18}$. For web-based applications in the cement industry, a new application based on the web for e-diagnostics called IzeeDiag. IzeeDiag is a web-based remote inspection platform that allows connecting a field technician with a distant expert ${ }^{19}$.

\section{Implementation of the Internet and Fuzzy Control System}

Implementation of the new network to control the cement kiln via Internet is divided on 2 parts. The first, to create the fuzzy controller using FuzzyControl++ Siemens tool. The second concerning the network to ensure the access via Internet and monitoring the cement kiln, e-diagnosis of alarms occurs, e-maintenance and e-fuzzy control. These innovations facilitate operators tasks, ensure production increased, reduced cyclone blockages and kiln ring formations, consistent quality with a reduction in standard deviation and more stable operation. Let us start with the cement process kiln and all details allows as creating the fuzzy controller.

\subsection{Cement kiln process}

We are interested in this work to the cement kiln, because an unstable kiln and cooler leads to inefficient production and inconsistent clinker quality. To keep kiln running safety, several interlocks must be respected. Different kiln equipments interlocks are presented in three next tables extracted from FLSmidth documents called "Function and Control Descriptions" FCDs presented in SCIMAT (AinTouta, Batna). Table 1 presents kiln drive interlocks and Table 2 presents kiln gas burner interlocks.

Kiln forced OFF when Kiln feed is on. Signal to use depends on the specific type and layout of kiln feed system. This is used during preheating of the kiln. After feed to the kiln has been started the interlocking between cooler and kiln drive must be working and cannot be bypassed unless the kiln is stopped (feed is off). Kiln feed typically started by switching a changeover gate to kiln instead of recirculating raw meal. Operator Force to $80 \%$ of current gas valve set point when Kiln inlet $\mathrm{CO}>\mathrm{HH}$ (delayed $10 \mathrm{sec}$ ) or Kiln inlet $\mathrm{CH}_{4}>\mathrm{HH}$ and all calciner burners are stopped (delayed $10 \mathrm{sec}$ ). If Ignition in operation, the logic is implemented in the local control panel, but included as an alarm for info to the operator. When the temperature of the last cyclone is $>750^{\circ} \mathrm{C}$ and the kiln feed has been on for $>30$ min the ignition supervision is disabled ${ }^{20}$.

\subsection{Creation of the fuzzy control using FuzzyControl++}

Complex industrial processes such as a batch chemical reactors, cement kilns and basic oxygen steel making are difficult to control automatically. This difficulty is due to their nonlinear, time varying behavior and the poor quality of available measurements. In such cases, automatic control is applied to those subsidiary variables, which can be measured and controlled, for example temperatures, pressures and flows. The overall process controls objectives, such as the quality and quantity of product produced, has been left in the hands of the human operators in the past ${ }^{21}$.

In recent years, computational intelligence has been used to solve many complex problems by developing intelligent systems. Fuzzy logic has proved to be a powerful tool for decision-making systems, such as expert and pattern classification systems. Fuzzy set theory has been used in some chemical process. In traditional rule-based approaches, knowledge encoded in the form of antecedent-consequent structure. When new data are encountered, it is matched to the antecedent's clause of each rule, and those rules where antecedents match a data exactly are fired, establishing the consequent clauses. This process continues until the desired conclusion is reached, or no new rule can be fired. In the past decade, fuzzy logic has proved to be useful for intelligent systems in chemical engineering.

Most control situations are more complex than we can deal with mathematically. In this situation fuzzy control can developed, provided a body of knowledge about the control process exists, and formed 
Table 1. Kiln drive interlocks.

\begin{tabular}{llll}
\hline Interlocking & Operator & Condition & Action \\
\hline $\begin{array}{l}\text { Protective } \\
\text { interlocking }\end{array}$ & Motor specific protection & $\begin{array}{l}\text { Motor bearing temperatures }<\mathrm{HH} \\
\text { and motor winding temperature }<\mathrm{HH}\end{array}$ \\
& & $\begin{array}{l}\text { Kiln bearing temperature }<\mathrm{HH}\left(65^{\circ} \mathrm{C}\right) \\
\text { protection against mechanical failure } \\
\text { Kiln drive gear lubrication }\end{array}$ & $\begin{array}{l}\text { include run signal from lubrication } \\
\text { pump, temperature and oil flow }\end{array}$ \\
& in operation alarm OK & protection against mechanical failure \\
& Kiln axial max. position alarm OK & protection against mechanical failure \\
& Kiln axial min. position alarm OK & krotection against mechanical failure \\
& Kiln axial position $<\mathrm{HH}(15 \mathrm{~mm})$ & protection against mechanical failure \\
& Kiln axial position $>\mathrm{LL}(-15 \mathrm{~mm})$ & Kiln drive and barring should not run \\
& Barring device stopped & & at the same time \\
\hline
\end{tabular}

Table 2. Kiln gas burner interlocks.

\begin{tabular}{|c|c|c|c|}
\hline Interlocking & Operator & Condition & Action \\
\hline \multirow[t]{3}{*}{$\begin{array}{l}\text { Safety } \\
\text { interlocking }\end{array}$} & AND & $\begin{array}{l}\text { ID fan stopped alarm OK. Bypassed } \\
\text { when the Cancel ID fan/burner } \\
\text { interlock is selected. }\end{array}$ & $\begin{array}{l}\text { The burner can be started without } \\
\text { the ID fan when preheating, } \\
\text { but if the ID fan is started and } \\
\text { trips the main burner must stop. }\end{array}$ \\
\hline & & Primary air fan running & The burner cannot run without primary air \\
\hline & & Main filter fan running & $\begin{array}{l}\text { During preheating the main filter fan } \\
\text { must be running }\end{array}$ \\
\hline $\begin{array}{l}\text { Start } \\
\text { interlocking }\end{array}$ & AND & $\begin{array}{l}\text { Preheater outlet analyzer in operation } \\
\text { Preheater outlet analyzer not in test mode } \\
\text { Igniter in operation }\end{array}$ & $\begin{array}{l}\text { Redundant interlocking. Logic is included in the } \\
\text { local control panel but included } \\
\text { to provide information to the operator }\end{array}$ \\
\hline
\end{tabular}


into a number of fuzzy rules. Fuzzy logic used for the early detection of hazardous states and for the implementation of decision-making logic. The fuzzy controller of the rotary kiln redesigned by using FuzzyControl++. FuzzyControl++ used to design the fuzzy parts of the controller, such as input/output membership functions and the rules, where this tool guarantee a continuous control. Fuzzy control of all parameters ensures the quality of product by following performer operations.

\subsubsection{FuzzyControl++}

Fuzzy logic is used today to an increasing extent in the automation of technical processes. An efficient tool for development and planning of process automation provided by FuzzyControl++, incorporating empirical process expertise and verbally formulated empirical knowledge.

FuzzyControl++ is a Siemens configuration tool for fuzzy logic. It offers solutions for non-linear controllers and for predicting the behavior of complex mathematical procedures from process automation, which are difficult or impossible to implement using standard tools.

FuzzyControl++ enables fuzzy systems to be developed and configured effectively for the automation of technical processes. Empirical process knowledge and verbally described experience can be implemented as fuzzy rules directly in open loop and closed-loop control, parameter adaptation of controllers, fault compensation and pre-control, pattern recognition, process data evaluation and diagnosis, automation of manual process interventions of a plant operator, process control with coordination of subordinate open loop and closed-loop controllers.

The configuration tool is used to configure and generate the fuzzy systems. During operation, the runtime software then executes the system, which are present in a data block 22 .

\subsubsection{Fuzzy controller of the rotary kiln}

The execution of fuzzy functions is a computationally intensive operation. The execution speed of specific fuzzy applications depends on the performance of the applied PLC. The more often the PLC has to calculate the output variables per time unit, the lower is the number of fuzzy applications that can be installed Processing times differ depending on the number of inputs/outputs, the number of rules and the programmable controller. In this work, we used S7-400 PLC, which insures for eight inputs, four outputs with five membership functions each and ten rules, four ms as a runtime execution. This advantage guarantee timeliness and speed functions execution.

In addition, with increased focus on cost reductions, many cement plants have started using alternative fuels for kiln and/or calcining firing. This has created more challenges for the operation of a kiln because of the different characteristics of different alternative fuels such as calorific value, moisture content and chemical composition. Each kiln has its own characteristics, limitations, operational challenges and control requirements. So the control system to deal with this complexity must be implemented in an environment that enables breaking down the complexity.

Some of those characteristics should be controlled such as, kiln feed, speed and fuel, calcining fuel, ID-fan speed and cooler grate and fan speed, others characteristics should be monitored, like, kiln inlet gas analyzer measurements, kiln temperatures and pressure, kiln torque, cooler pressure and temperatures. Fig. 5. presents different parameters to control, from Pre-heater (cyclones) to kiln fuel.

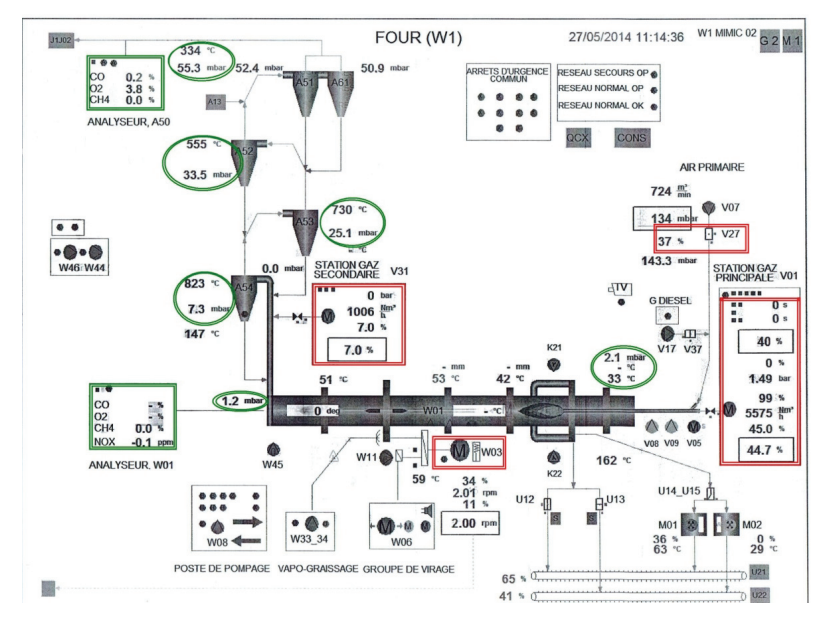

Fig. 5. Fuzzy control parameters of the rotary kiln.

The independent use of fan speed and fuel rate 
is constrained by the fact that there must always be sufficient oxygen available to burn the fuel, and in particular, to burn carbon to carbon-dioxide.

If carbon monoxide formed, this represents a waste of fuel, and indicates reducing conditions within the kiln, which must be avoided at all costs since it causes destruction of the clinker mineral structure. For this reason, the exhaust gas is continually analyzed for $\mathrm{O}_{2}, \mathrm{CO}$ and $\mathrm{CH}_{4}$ as shown in Table 3 .

Table 3. Analyzer gases and causes of variation.

\begin{tabular}{lc} 
If & Then \\
\hline $\mathrm{O}_{2}$ increased & Gas reduced or fan speed increased \\
$\mathrm{O}_{2}$ reduced & Gas increased or fan speed reduced \\
$\mathrm{CO}$ increased & Fan speed reduced \\
$\mathrm{CH}_{4}$ increased & more gas inlet kiln \\
\hline
\end{tabular}

To react correctly to conditions, operators should be select the good decision. Different conditions need corrective actions.

Table 4. presents several control conditions of analyzer gases parameters and their correspondent corrective actions.

Cyclone temperature indicators shows the degree of drying material. Cyclone's temperatures $\left({ }^{\circ} \mathrm{C}\right)$ are generated from the material mixture and hot gases (the exchange of heat between the material and hot kiln gases).

Table 5. shows temperatures of different cyclone stages with stability ranges and deviations with the maintenance action or appropriate response.

Pressure of cyclones is controlled to ensure the circulation of hot gases for heat exchange with the feed, to avoid tamping cyclone and the return of feed to the filter.

Table 6. presents pressure (mbar) control conditions and appropriate corrective actions in cyclones A50, A52 and A53.
Table 6. Pressure control.

\begin{tabular}{|c|c|c|c|}
\hline Param & Range & Deviation & Corrective action \\
\hline \multirow{3}{*}{$\mathrm{A} 50 \mathrm{P} 1$} & $\operatorname{Max}=80$ & $\mathrm{~A} 50 \mathrm{~T} 1>80$ & Increase fan speed \\
\hline & $\mathrm{Pc}=49$ & & \\
\hline & $\operatorname{Min}=20$ & A50T1 $<20$ & Reduce fan speed \\
\hline \multirow{3}{*}{$\mathrm{A} 52 \mathrm{P} 1$} & $\operatorname{Max}=60$ & $\mathrm{~A} 52 \mathrm{~T} 1>65$ & Increase fan speed \\
\hline & $\mathrm{Pc}=33$ & & \\
\hline & Min $=15$ & A $52 \mathrm{~T} 1<15$ & Reduce fan speed \\
\hline \multirow{3}{*}{ A53P1 } & $\operatorname{Max}=40$ & $\mathrm{~A} 53 \mathrm{~T} 1>40$ & Increase fan speed \\
\hline & $\mathrm{Pc}=23$ & & \\
\hline & $\operatorname{Min}=5$ & A53T $1<5$ & Reduce fan speed \\
\hline \multirow{3}{*}{ A54P1 } & $\operatorname{Max}=30$ & $\mathrm{~A} 54 \mathrm{~T} 1>30$ & Increase fan speed \\
\hline & $\mathrm{Pc}=8$ & & \\
\hline & $\operatorname{Min}=5$ & A54T1 $<5$ & Reduce fan speed \\
\hline
\end{tabular}

Possibilities to study all analogue values, and their chronological development can be reproduced graphically. Fuzzy control of the kiln is essentially based on the routine described above.

Fuzzy control is an automatic control of the kiln through which the operator first sets the kiln in stable state and then let the computer control the settings, having provided some set-points related to the existing operation of the kiln.

Table 7. shows the range of one of parameters of control, which is the temperature $\left({ }^{\circ} \mathrm{C}\right)$ in the interior of kiln (W) and intervention in case of deviations with their corresponding corrective actions:

The ideal speed rotation of the kiln is $2 \mathrm{tr} / \mathrm{min}$. The rotation is transmitted to it by the ring gear, the pinion and reducer. The high-speed modern kilns are normally equipped with two pinions. The sprockets are coupled to the speed reducer via a torsion shaft.

The kiln can be turned independently of the main engine turning gear and auxiliary engine. The kiln is fed by the buffer hopper.

The debit-meter control opening of the register so that the selected amount of raw meal be sent to the furnace. Materials transport to the kiln is done using a pneumatic loading or through the Fuller pump. 
Table 4. Analyzer gases parameters in cyclone A50.

\begin{tabular}{llll}
\hline Cyclone parameters & Range & Limit & Corrective action \\
\hline A50A1 $(\mathrm{CO}) \%$ & Max $=0.25$ & A50A1 $>0.25$ & Increase fan speed \\
& $\mathrm{Pc}=0.10$ & & \\
& Min $=0.00$ & & Reduce gas \\
A50A2 $\left(\mathrm{CH}_{4}\right) \%$ & $\mathrm{Max}=0.10$ & A50A2 $>0.1$ & Increase fan speed \\
& $\mathrm{Pc}=0.00$ & & \\
& $\mathrm{Min}=0.00$ & & Reduce gas \\
A50A3 $\left(\mathrm{O}_{2}\right) \%$ & $\mathrm{Max}=5$ & A50A3 $>5$ & Reduce fan speed \\
& $\mathrm{Pc}=4$ & & \\
& Min $=2$ & A50A3 $<2$ & Increase fan speed \\
\hline
\end{tabular}

Table 5. Temperature control in cyclones.

\begin{tabular}{llll}
\hline Parameters & Range & Deviations & Corrective action \\
\hline \multirow{2}{*}{ A50T1 } & $\begin{array}{l}\text { Max }=350 \\
\mathrm{Pc}=325\end{array}$ & A50T1 $>350$ & Increase feed and Reduce fan speed \\
& Min $=300$ & A50T1 $<300$ & Reduce fee and Increase fan speed \\
& Max $=555$ & A52T1 $>555$ & Reduce gas and Increase feed \\
A52T1 & $\begin{array}{l}\mathrm{Pc}=540 \\
\text { Min }=530\end{array}$ & A52T1 $<530$ & Increase gas and Reduce feed \\
& $\begin{array}{l}\text { Max }=760 \\
\text { Ac }=730\end{array}$ & A53T1 $>760$ & Reduce gas and Increase feed \\
A53T1 & Min $=700$ & A53T1 $<700$ & Increase gas and Reduce feed \\
& Max $=860$ & A54T1 $>860$ & Reduce gas and Increase feed \\
A54T1 $=840$ & & \\
& Min $=820$ & A54T1 $<820$ & Increase gas and Reduce feed \\
\hline
\end{tabular}

Table 7. Kiln temperature control.

\begin{tabular}{|c|c|c|c|}
\hline Param & Range & Limit & Actions \\
\hline \multirow{3}{*}{ W01T4 } & $\operatorname{Max}=1450$ & $\mathrm{~T} 4>1450$ & Reduce gas \& Increase feec \\
\hline & $\mathrm{PC}=1300$ & & \\
\hline & $\operatorname{Min}=1200$ & $\mathrm{~T} 4<1200$ & Increase gas \& Reduce feec \\
\hline
\end{tabular}


Feeding the kiln by raw meal is synchronized by the kiln rotational speed that is to say if the kiln speed is increased then the raw meal supply is increased but not the reverse (if supply increases, the kiln rotational speed remains the same). Proportionality between speed and feed kiln is summarized in Table 8 .

Table 8. Relation between rotary kiln's speed and feed.

\begin{tabular}{lc}
\hline Speed (t/mn) & feed (tonnes) \\
\hline 1 & 58 \\
1,1 & 63 \\
1,2 & 69 \\
1,3 & 75 \\
1,4 & 81 \\
1,5 & 86 \\
1,6 & 92 \\
1,7 & 98 \\
1,8 & 104 \\
1,9 & 109 \\
2,0 & 115 \\
\hline
\end{tabular}

According to all these details, the fuzzy controller of the cement kiln contains many fuzzy inputs and outputs.

Fig. 6. presents the file created by FuzzyControl++, with eight inputs and four outputs.

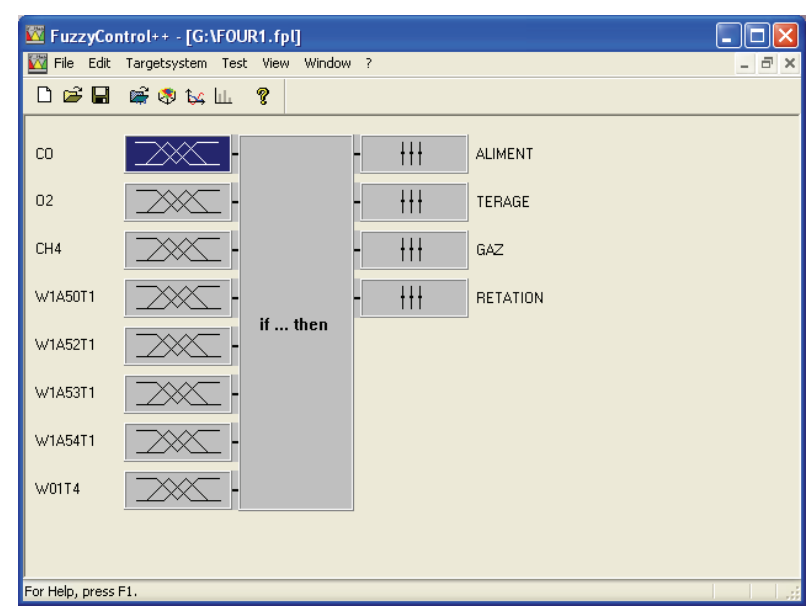

Fig. 6. The fuzzy controller of the rotary kiln.

Fig. 7(a). and (b). presents an example of $\mathrm{CO}$ (for kiln inlet gas analyzer) input and Gas (fuel) output.

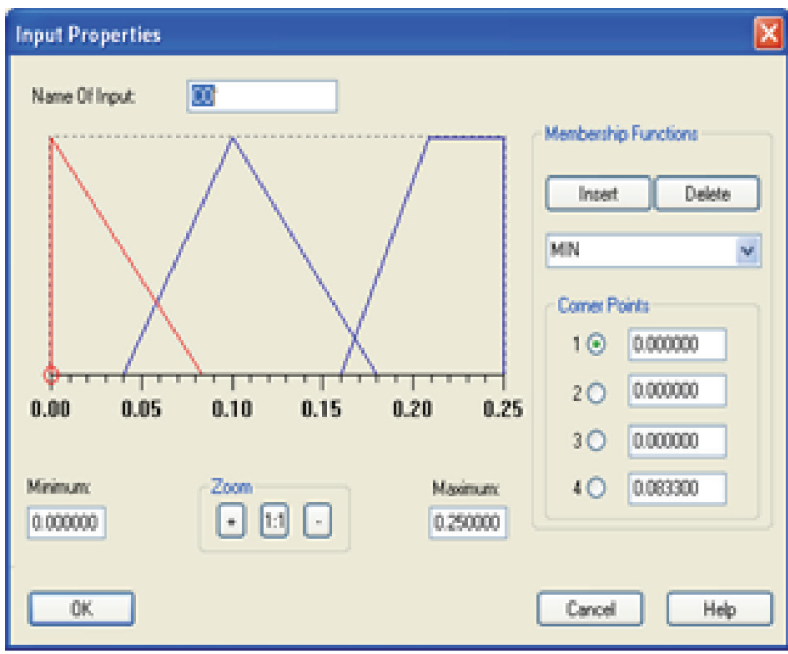

(a)

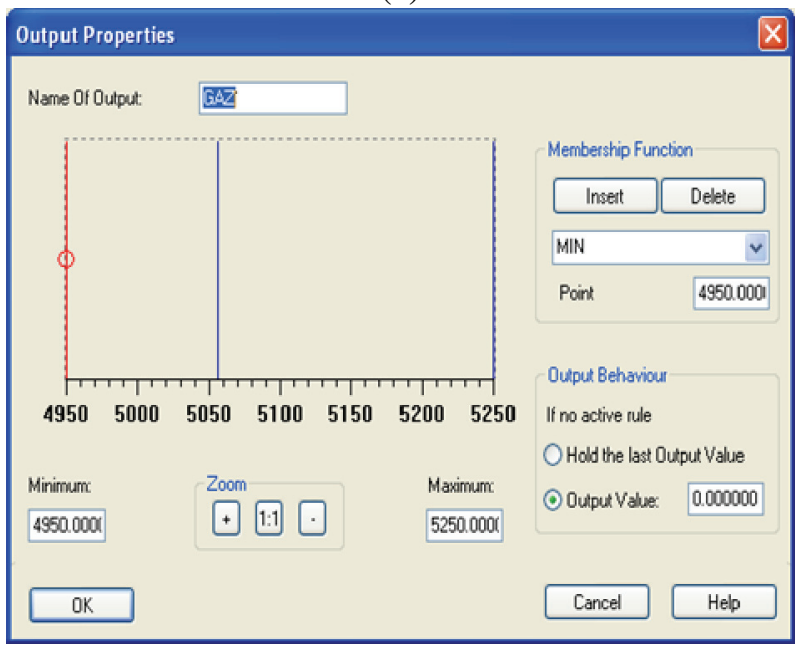

(b)

Fig. 7. Inputs and outputs of the fuzzy controller.

The fuzzy controller is created to control the system from preheater to the cooler. Table 9. presents some fuzzy rules.

Fig. 8. presents the rule table contains all fuzzy rules needed to control the cement rotary kiln in our system created by using FuzzyControl++. 
Table 9. Fuzzy rules.

\begin{tabular}{ll}
\hline Condition & Action \\
\hline if $\mathrm{O}_{2}>$ Max & Reduce fan speed \\
if $\mathrm{O}_{2}<$ Min & Increase fan speed \\
if $\mathrm{CH}_{4}>$ Max & Increase fan speed \\
& and reduce Gas \\
if $\mathrm{CO}>$ Max & Increase fan speed \\
& and reduce gas \\
if cyclone temperature $>$ Max & Reduce gas \\
& and increase feed \\
if cyclone temperature $<$ Min & Increase gas \\
& and reduce feed \\
\hline
\end{tabular}

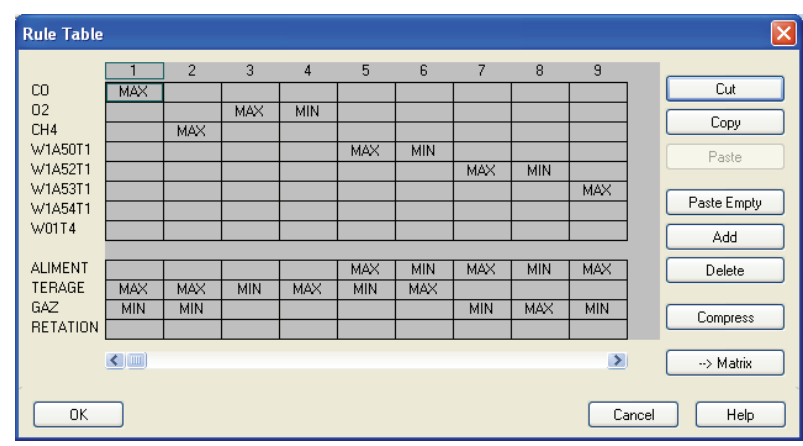

Fig. 8. Rule table of the fuzzy controller of the cement kiln.

\subsection{Creation of the web architecture}

\subsubsection{Access to the Web Server}

The system provides a set of analytical tools for interactive data display and analysis of current process states and historical data. The client evaluates and display process values in data server or long-term archive server system. User-name and password of the operator are configured using the User Administrator tool.

\subsubsection{Remote fuzzy control of the rotary kiln via Internet}

The OS Web server stores all views and scripts necessary to enable them to display and run on the Web client. All views and all scripts that must be prepared (published) for this purpose done using the
Web View Publisher tool. The operator can connect to the Web client and access data from the OS Web server via a TCP/IP connection. The display in the Internet Explorer user interface corresponds to the operator station (OS), with overview area, work area, and function keys.

The system provides a set of analytical tools for interactive data display and analysis of current process states and historical data. The Web client can evaluate and display process values in the data server. The process screens used exclusively for supervision and navigation in process screens with the MS Internet Explorer browser. Moreover, it will be used to perform the same mechanism as the server for communication, user management, and representation of graphical data. Fig. 9. shows the Internet-based system for cement kiln process.

\subsection{Alarm diagnosis and maintenance}

In the OS Web client, several alarms occur during running of the raw mill workshop. Each alarm displays a maintenance action to be performed. For example, if an alarm indicates that the mill outlet depression is high, the alarm causes halt of the mill, the elevator, and after that, the separator. The alarm is displayed in the top bar of the view and appears in the alarm table.

Alarms are created using WinCC Alarm Logging. There are several types of alarm. Each color indicates a category of an alarm or its level of danger (high "red"), or other type according to the diversity of alarms (warning, intervention, etc.). Fig. 10. illustrates some alarms and maintenance actions.

\subsection{Trends and data analyzing via Internet}

Trends as shown in Fig. 11. are used to display the most recent historical values on a graph. The graphs $y$-axis represents the point value and the $\mathrm{x}$-axis represents time. The entire trend window covers a period called the trend horizon. The right most fourth of the trend is called the update horizon.

The trend window is updated with values each time a pre-assigned update period expires. Periodically, the system saves values of all A-points and the statistical information for all points to a historical data 
file.

\section{Security of the Remote Fuzzy Control System}

As the use of Ethernet connections all the way down to the field level increases, the associated security issues are becoming a more urgent topic for industry. After all, open communication and increased networking of production systems involve not only huge opportunities, but also high risks.

To provide an industrial plant with comprehensive security protection against attacks, the appropriate measures must be taken. Siemens can support you here in selectively implementing these measures within the scope of an integrated range for Industrial Security.

Network security means protecting automation networks from unauthorized access. This includes the monitoring of all interfaces such as the interfaces between office and plant networks or the remote maintenance access to the Internet, which can be accomplished by means of firewalls.

The secure segmenting of the plant network into individually protected automation cells minimizes risks and increases security. Cell division and device assignment are based on communication and protection requirements.

Data transmission is encrypted by means of a VPN and is thus protected from data espionage and manipulation. The communication stations are securely authenticated. The cell protection concept can be implemented and communication can be secured using "Security Integrated" components such as SCALANCE S Security Modules, SOFTNET Security Client or The Automation Firewall.

\subsection{SCALANCE S}

Security modules for the protection of automation networks and security during data exchange between automation systems. The security modules of the SCALANCE S range can be used to protect all devices of an Ethernet network against unauthorized access. In addition, SCALANCE $S$ also protect the data transmission between devices or network segments (e.g. automation cells) against data manipula- tion and espionage; they can also be used for secure remote access over the Internet.

The security modules can be operated not only in bridge mode but also in router mode, and can thus be used direct at IP subnetwork borders. Secure remote access over the Internet or GPRS/UMTS/LTE is possible with the GPRS/UMTS/LTE routers. SCALANCE $\mathrm{S}$ is optimized for use in automation and industrial environments, and meets the specific requirements of automation systems, such as easy upgrades of existing systems, simple installation and minimal downtimes in the event of a fault.

The firewall can be used as an alternative or to supplement VPN with flexible access control. The firewall filters data packets and disables or enables communication links in accordance with the filter list and stateful inspection.

Both incoming and outgoing communication can be filtered, either according to IP and MAC addresses as well as communication protocols (ports) or userspecific. The Security Module in a log file saves access data. Enables detection of how, when and by whom the network has been accessed as well as detecting access attempts, enabling appropriate preventative measures to be taken ${ }^{23}$.

\subsection{SOFTNET Security Client}

The SOFTNET Security Client is a component of the Industrial Security concept for protecting programmable controllers and for security during data exchange between automation systems. It is a VPN client for programming devices, PCs and notebooks in industrial environments and supports secure client access via LAN or even WAN (e.g. for remote maintenance via the Internet) to automation systems protected by Security Integrated devices with VPN functionality.

Data transmission is protected against operator error, eavesdropping/espionage and manipulation; communication can only take place between authenticated and authorized devices. The SOFTNET Security Client uses field-proven IPsec mechanisms for setting up and operating VPNs.

In addition, guaranteed the avoidance of system disruptions through exclusive access to programmable controllers or complete automation cells using ap- 
proved programming devices or notebooks, and it presents a high flexibility when used on mobile PCs as no hardware is required for safeguarding the communication.

The security modules of the SCALANCE S family are provided specially for use in automation, yet connect seamlessly with the security structures of the office and IT world. They provide security and meet the specific requirements of automation technology, such as simple upgrades of existing systems, simple installation and minimum downtimes if a fault occurs. Depending on the particular security needs, various different security measures can be combined.

The SOFTNET Security Client allows programming devices, PCs, and notebooks access to devices with IPSec VPN functionality.

Since IP addresses can be falsified (IP spoofing), checking the IP address (of the client access) is not sufficient for reliable authentication. In addition to this, Client PCs may have changing IP addresses. For this reason, the authentication is performed using tried and tested VPN mechanisms.

For data encryption, secure encryption is necessary to protect data traffic from espionage and manipulation. This means that the data traffic remains incomprehensible to any eavesdropper in the network.

With using the associated configuration tool, it is possible to create and manage security rules even without special security knowledge. In the simplest case, only the SCALANCE S modules or SOFTNET Security Clients that will communicate with each other are created and configured. As soon as SOFTNET Security Client knows the programmable controllers to be accessed, communication can be established [23].

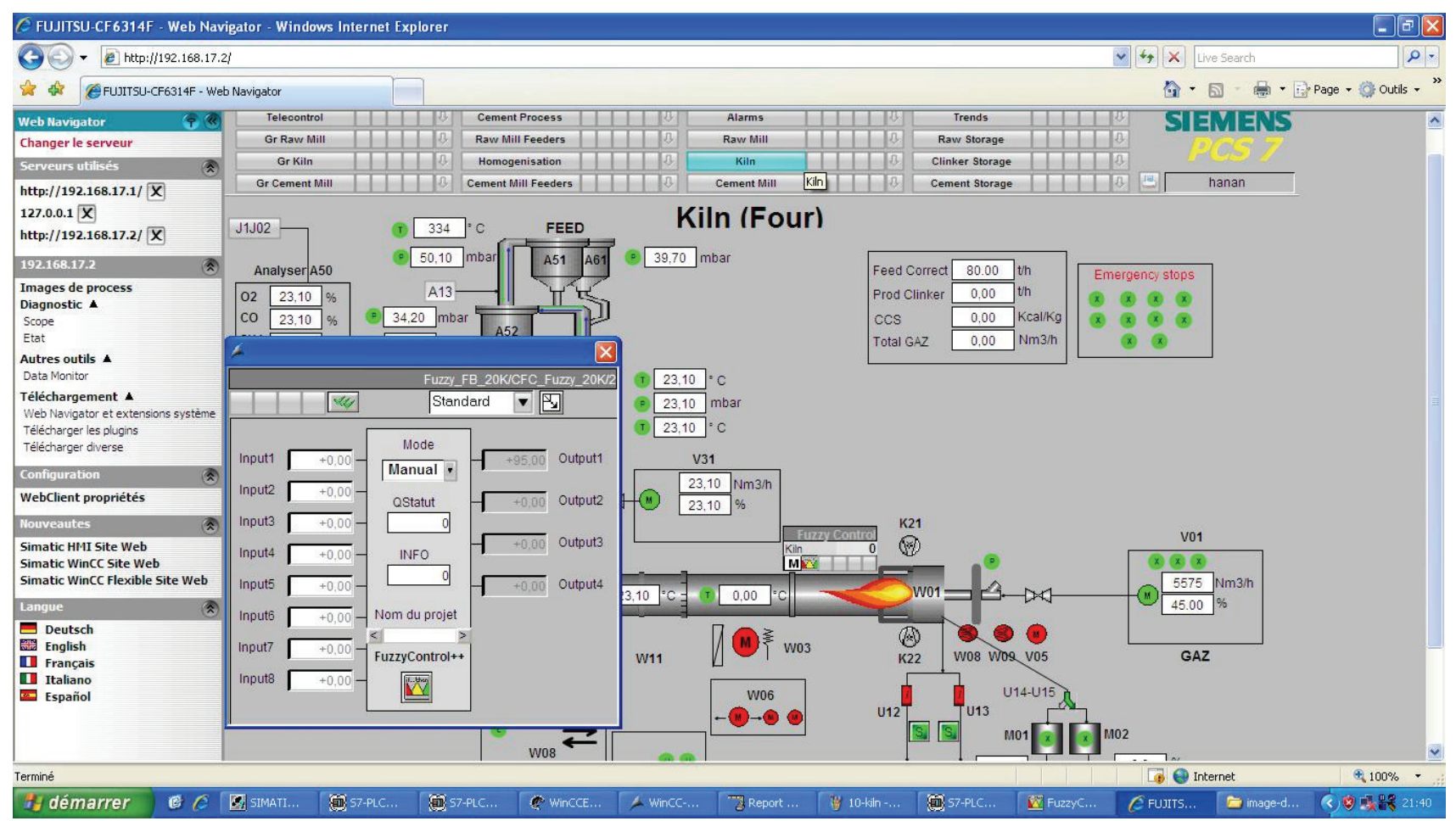

Fig. 9. Fuzzy control of the cement kiln via Internet. 


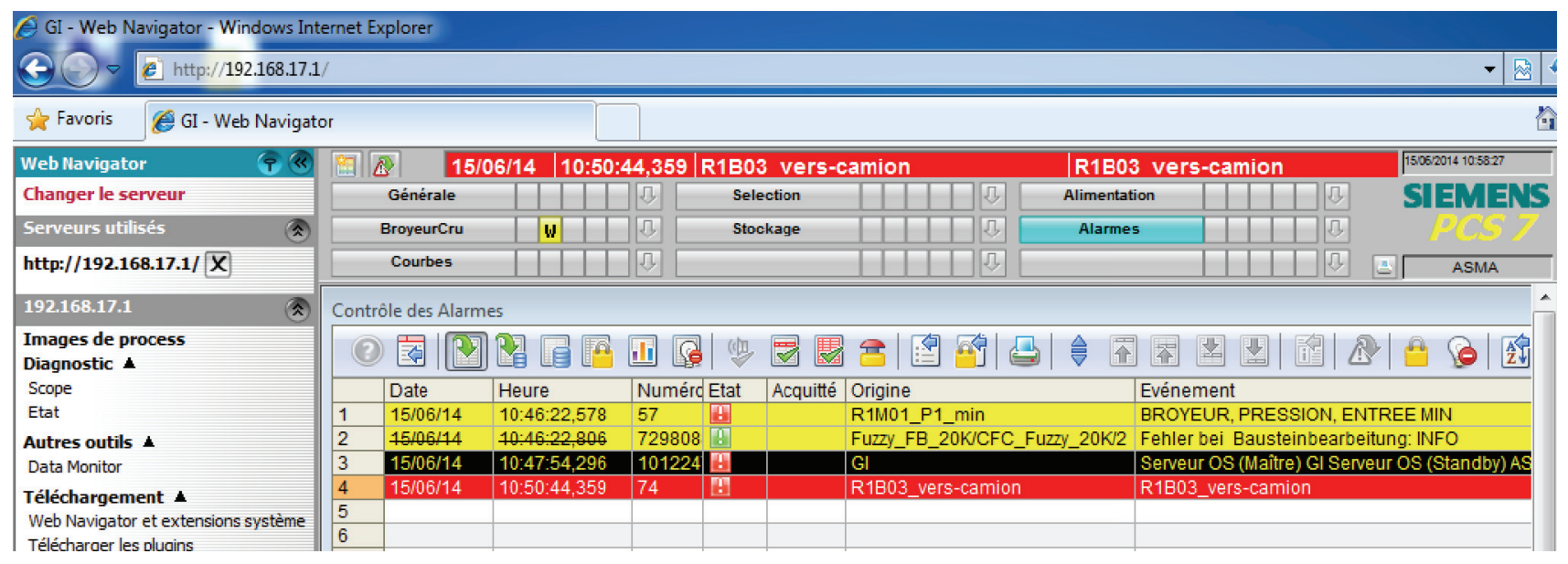

Fig. 10. Alarms diagnostic and maintenance via Internet.

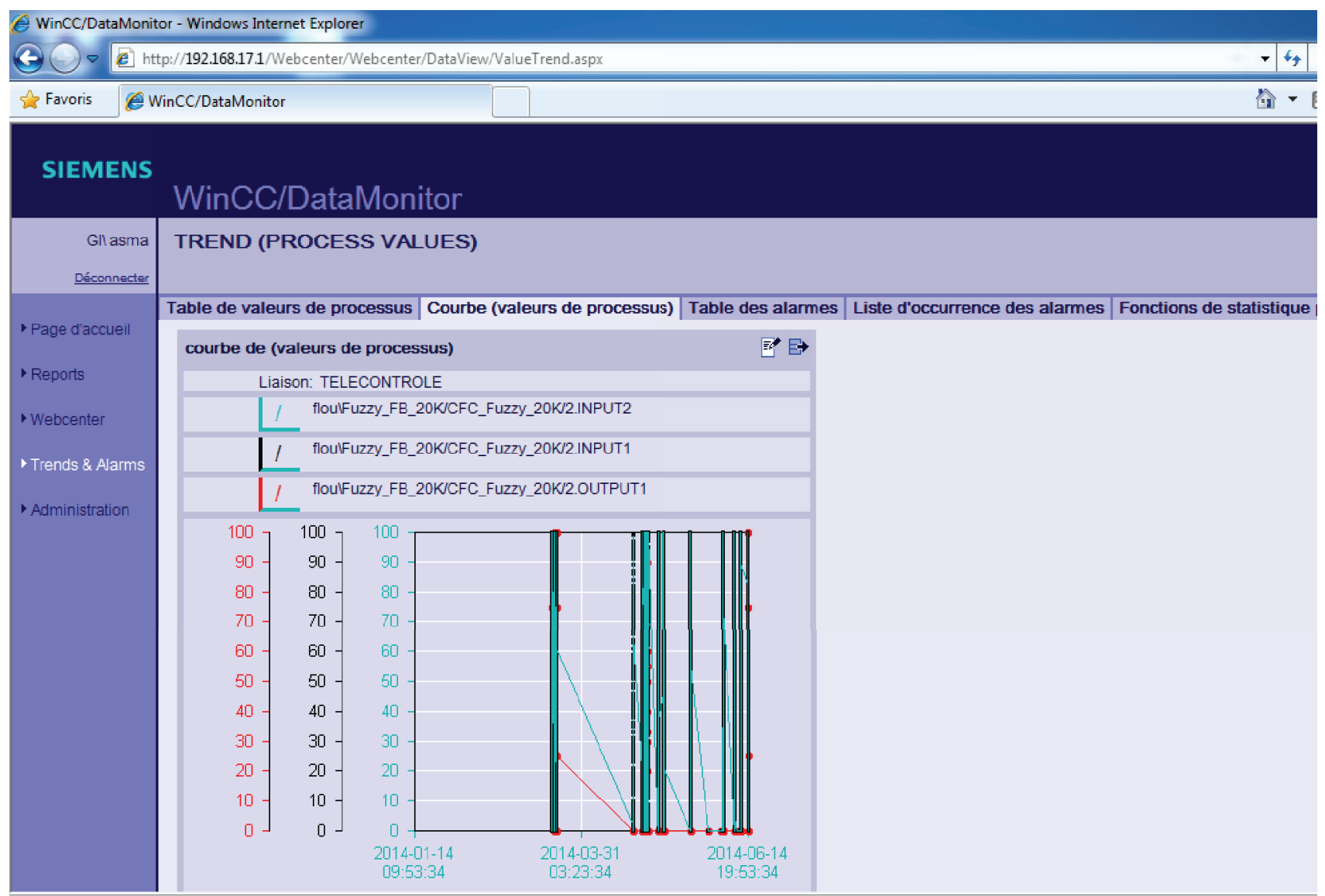

Fig. 11. Trends analyzing via Internet. 


\section{Conclusion}

To compete in successfully today, is challenging world economy; companies often require innovative solutions to make their plant operating systems function at peak efficiency. Utilizing the latest in equipment technology, resources, and materials. However, complex industrial processes are difficult to control because of inadequate knowledge of their behavior.

This lack of knowledge is principally a lack of structural detail and it is this, which prevents the use of conventional control theory. However, these processes often controlled with great skill by a human operator who makes decisions based on inexact and linguistic measures of the process state. Fuzzy logic considered as a superset of standard logic, which extended to deal with the partial truth. It has become one of the most successful technologies for developing complex control systems.

Optimizing cement plant processes is a complex task that requires cement production knowhow and the use of supporting sophisticated technologies such as Artificial Intelligence techniques. Fuzzy logic is an Artificial Intelligence design methodology that can used to solve real life problems.

Chemical engineering has employed fuzzy logic in the piping risk assessment, safety analysis, batch crystallizer, combustion process, Food Produce, fluidized catalytic cracking Unit and separation Process. It has also applied to process control and kinetics.

In this work, we presented a new architecture based on remote of a fuzzy control system using Internet access to the cement kiln process. Several Siemens tools used to implement this architecture, such as Step 7, WinCC/DataMonitor, WinCC/WebNavigator, FuzzyControl++, and other tools.

Cement factories in Algeria used as case studies in this work to optimize operator's tasks and applied artificial intelligence. In this work, we are used fuzzy logic, and for perspectives, we hope to use neural networks or fuzzy neural networks. In addition to protect human lives from dangerous and risks in complex industrial systems, we proposed to use Internet to control these systems remotely.

\section{Acknowledgments}

I would like to take this opportunity to express my profound gratitude and deep regard to Pr. H. Mouss, for her exemplary guidance, valuable feedback and constant encouragement throughout the duration of the project. Her valuable suggestions were of immense help throughout my project work. Her perceptive criticism kept me working to make this project in a much better way. Working under her was an extremely knowledgeable experience for me. This project would have been impossible without the support of the operators of cement factories, SCIMAT, SCAEK. I would also like to give my sincere gratitude to all the friends and colleagues who filled in the survey, without which this research would be incomplete.

\section{References}

1. L. Zadeh, Outline of a new approach to the analysis of complex systems and decision processes, in IEEE Trans. Syst., Man, Cybern. SMC-3, (1973) 28-44.

2. L. Zadeh, The Concept of a Linguistic Variable and its Application to Approximate Reasoning, in Information Sciences, I, 8 (1975) 199-249.

3. Regain Technologies Pty Ltd, How is Portland clinker and cement manufactured? http://www.regainmaterials.com/cement-

industry/value-generation-in-cement-

production/cement-manufacturing-process, consult (2016)

4. M. Sha Sadeghi, N. Vafamand, More relaxed stability conditions for fuzzy TS control systems by optimal determination of membership function information, in Journal of Control Engineering and Applied Informatics, 16 (2) (2014) 67-77.

5. H. Khebbache, M. Tadjine, Robust Fuzzy Backstepping Sliding Mode Controller for a Quad-rotor Unmanned Aerial Vehicle, in Journal of Control Engineering and Applied Informatics, 15 (2) (2013) 3-11.

6. T. Takagi and M. Sugeno, Fuzzy identification of systems and its applications to modelling and control, in IEEE Transactions on Systems. Man and Cybereitics, SMC-15 (1) (1985) 116-132.

7. F. L. Smidth Automation, Process Expert Monitor, User manual, Denmark, (1998).

8. F. L. Smidth Automation. ECS/ProcessExpert-Kiln, User manual, Denmark, (2007) PP-7004.PXP.0001.

9. R. M. Parkin and C. A. Czarnecki, A PID Servo Control System Experiment Conducted Remotely via In- 
ternet, in Journal of Mechatronics, 12 (6) (2002) 833843.

10. S. H. Yang, X. Chen and J. L. Alty, Design issues and implementation of internet-based process control systems, in Journal of Control Engineering Practice, 11 (6) (2003) 709-720.

11. H. A. Thompson, Wireless and Internet communications technologies for monitoring and control, in Journal of Control Engineering Practice, 12 (6) (2004) 781-791.

12. B. Qiu and H. B. Gooi, Web-Based SCADA Display Systems (WSDS) for Access via Internet, in IEEE Transactions on Power Systems, 15 (2) (2000) 681686.

13. W. F. Chang, Y. C. Wu and C. W. Chiu, Development of a web-based remote load supervision and control system, in Journal of Electrical Power and Energy Systems, 28 (6) (2006) 401-407.

14. M. Dominguez, J. J. Fuertes, P. Regueraa, I. Diaz and A. A. Cuadrado, Internet-based remote supervision of industrial processes using self-organising maps, in Engineering Applications of Artificial Intelligence, 20 (6) (2007) 757-765.

15. C. Sahin and E. D. Bolat, Development of remote control and monitoring of web-based distributed OPC system, in Journal of Computer Standards and Interfaces, 31 (5) (2009) 984-993.
16. A. Rogowski, Web-based remote voice control of robotized cells', in Journal of Robotics and ComputerIntegrated Manufacturing, 29 (4) (2013) 77-89.

17. I. Yabanova, S. Taskin and H. Ekiz, Development of remote monitoring and control system for mechatronics engineering practice: The case of flexible manufacturing system, in International Journal of Electrical Engineering Education, 52 (3) (2015) 264-275.

18. W. J. Li, S. C. Tung and S. M. Huang, Web-Based Supervisory Control System Based on Raspberry Pi, in Applied Mechanics and Materials, 764-765 (2015) 640-643.

19. Apizee, IzeeDiag Remote diagnostic solution for your enterprise. http://apizee.com/izeediag/, (2014).

20. F. L. Smidth Automation, Documents Function and Control Descriptions FCDs, SCIMAT (Ain-Touta, Batna, Algeria), Denmark, (2008).

21. P. J. King, E. H. Mamdani, The application of fuzzy control system to industrial processes. in Automatica, 13 (3) (1977) 235-242.

22. Siemens AG, Add-ons for the SIMATIC PCS 7 Process Control System, Catalog ST PCS 7 AO, Germany, (2013).

23. Siemens AG. SIMATIC Net, Scalance S and Softnet Security Client Operating Instructions, User manual, (2011) C79000-G8976-C196-0. 